\title{
An experimental study on the durability properties of abaca fiber concrete
}

DOI:10.36909/jer.ACMM.16351

\author{
Reynold Anthony, Swati Suhalka, Afsal S., V.R. Prasath Kumar*
}

Department of Civil Engineering, SRM Institute of Science and Technology, Kattankulathur 603203, Tamil Nadu, India.

*Email: prasathv@srmist.edu.in; Corresponding Author.

\begin{abstract}
The addition of natural fibers in concrete has effectively proved to increase the mechanical strength and durability of concrete in the recent years. They help to tackle the brittle response and limiting post-yield energy absorption by forming a bridge across the cracks in concrete. This study assesses the durability properties of abaca fiber reinforced concrete (AFRC) by surface water absorption test, rapid chloride permeability test (RCPT) and sorptivity test. The optimum percentage of abaca fiber (AF) to be used was chosen to be $0.5 \%$ as it gave the maximum compressive strength value in concrete and a small amount of superplasticizer has been added to reduce the water content in the mix design to match the high water absorption capability of AF. The respective tests were performed to observe the improved properties of water resistance and resistance to chloride ions penetration after 3, 7, 28, 56, 90 and 180 days of curing. It has been found that the addition of AF enhances the ability of concrete to reduce permeability better compared to the effect of conventional concrete (CC).
\end{abstract}

Keywords: abaca fiber; abaca fiber reinforced concrete; durability properties; water resistance; chloride ions penetration. 


\section{INTRODUCTION}

The utilization of fiber reinforced concrete as a construction material has gained attention in the recent years due to the wide applicability in the industry. It is known that concrete structures are usually exposed to harsh environments and it has to be highly durable to endure for a prolonged period of time with bare minimum level of maintenance (Stanish et al., 1997). $\mathrm{CC}$ is said to be low in flexure and deflection resistance as the reason for the lack of strength was found to be the crack formations in concrete (Grace, 2016). The addition of fiber aids in bridging across the cracks to increase mechanical strength, toughness, ductility and to obtain improved durability properties (Afroughsabet \& Ozbakkaloglu, 2015 and Asvin, 2016). They help to reduce permeability, control plastic and drying shrinkage by arresting the propagation of cracks and improve the resistance of concrete to weathering, abrasion and corrosion by chemicals better compared to CC (Saandeepani \& Krishnamurthy, 2013 and Sivaraja et al., 2010). The natural fibers tend to possess certain advantages like easy availability, light weight, low cost, high tensile strength and stiffness (Balasubramanian et al., 2015). They are adsorbent, eco-friendly and more durable compared to the synthetic fibers available in the market. The addition of natural fibers in concrete has been identified as a way to produce a more homogeneous concrete with improved mechanical properties and higher energy absorption capacity by regulating the propagation of cracks (Teng et al., 2018). The natural fibers are gaining popularity as cementitious material reinforcement so as to meet the requirements of sustainable development in the construction industry (Jianqiang et al., 2016). The AF belonging to the banana family of plants is regarded to be one of the robust of all existing natural fibers with high tensile and folding strength, buoyancy, high porosity and good resistance to saltwater damage (Vijayalakshmi et al., 2014). They are widely grown in the Philippines and the by-product is harvested as fiber without incurring any additional costs as it is manually or mechanically stripped from the sheath in leaves, washed and dried 
for further use. Being fine, radiant, light beige in colour and robust are considered to be the best qualities of AF. They are utilized for the manufacture of many products such as ropes, tea bags, specialty papers like security papers and cigarette papers and more (Richter et al., 2013). They are also used for the manufacturing of roofing and low-cost cladding materials for various structures due to their abundant growth in many developing countries (Elie et al., 2012). The elements such as cellulose (56 - $68 \%)$, hemicellulose (19 - 25\%), lignin (5 - 13 $\%)$, cuticula $(0.2-3 \%)$, pectin $(0.5-1 \%)$, lipid and water content of $1.4 \%$ makes up the chemical composition (Richter et al., 2013 and Wahyuna et al., 2018). The structure of the cell walls gives high tensile strength and the presence of high levels of lignin and cellulose affects the versatility of AF (Müssig \& Christian, 2010). Bio-degradability, fire resistance and water absorption are some of the mechanical properties that have a significant effect through it (Indrana et al., 2014). It is stated that the various mechanical strength properties and durability properties are often regarded as the most important criteria in concrete composites and these criteria plays a major role in structures which are exposed to hazardous marine environments (Mahyuddin et al., 2013). The aim of this study is to extend an experimental investigation on the durability properties of AFRC to observe the improved properties of water resistance and resistance to chloride ions penetration in a time period of six months.

\section{EXPERIMENTAL STUDY}

\section{Materials Used}

The AF was obtained from a well-known source through the internet for this study and it was shipped in long strips that were dried in sunlight for about 24 hours to remove any presence of moisture content in it. It was important to determine the aspect ratio of the AF which was found to be 104 by calculating the average diameter at the mid and at the end section of the fiber and by considering a short length of $40 \mathrm{~mm}$ of the fiber to be used in the concrete design mix. The AF which was shipped in long strips has been shown in Figure 1 while the AF after 
it was cut into short lengths of $40 \mathrm{~mm}$ has been shown in Figure 2. It has been proved that short fibers have the ability to quickly disperse in a homogeneous manner throughout the composite material which aids to arrest cracks more effectively compared to long fibers (Coutts \& Warden, 1987). The cement used for the study was OPC of 53 grade with a specific gravity of 3.11 and it was made sure to be used within three months from the date of manufacture as per the test proceedings. M-Sand with a specify gravity of 2.62 was used as fine aggregates as it is less disruptive to the environment compared to river sand and it was graded properly to get the least void ratio and to keep it free from silt, clay and other defilements while $12 \mathrm{~mm}$ size aggregates with a specific gravity of 2.75 were used as coarse aggregates which were washed thoroughly to remove the presence of any dust particles and were dried in sunlight for about 24 hours.

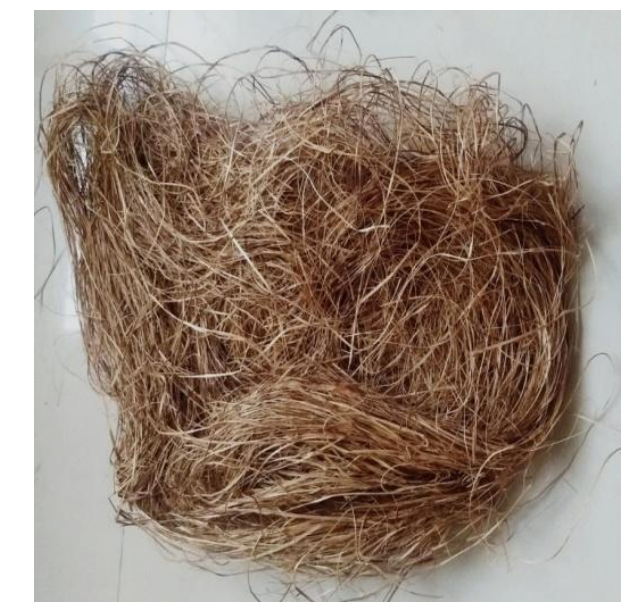

Figure 1 AF in long strips

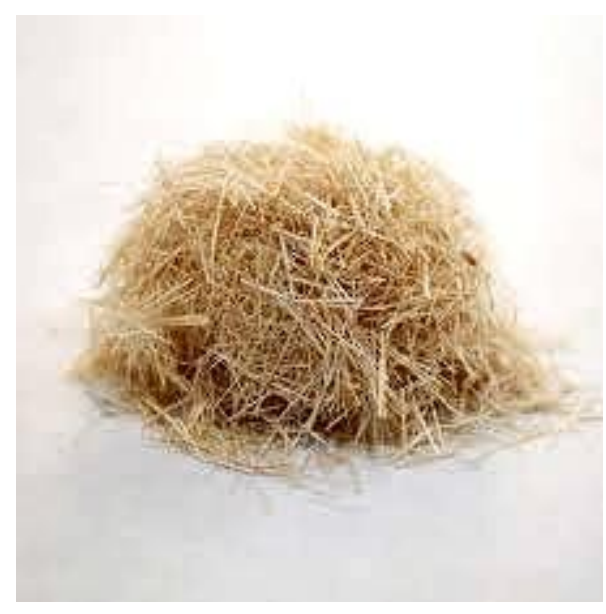

Figure 2 AF cut into short lengths

\section{Mix Design}

The mix design for concrete of M40 grade was designed to be 1:2.2:3.1 in accordance with the respective standards and the w/c ratio was chosen as 0.4 (IS $10262: 2009$ ). It was followed by the addition of $1 \%$ of superplasticizer which has proved to minimize the excess water content in the concrete design mix and to give the highest strength in fiber reinforced concrete under prolonged curing (Yilmaz et al., 2008). 


\section{Casting of Test Specimens}

The cubical specimens that were cast for carrying out the compressive strength test were of $150 \mathrm{~mm} \times 150 \mathrm{~mm} \times 150 \mathrm{~mm}$ in size, the cylindrical specimens that were cast for carrying out the surface water absorption test were of $100 \mathrm{~mm}$ in diameter and $200 \mathrm{~mm}$ in height. The cylindrical specimens were cast again and were further cut into discs of $100 \mathrm{~mm}$ in diameter and $50 \mathrm{~mm}$ in height for carrying out the RCPT and the sorptivity test. They were cast with the addition of $0,0.5,1.0$ and $1.5 \%$ of AF respectively in accordance with the respective mix design and as per the requirements of the tests that were performed in this study.

\section{Methods of Testing}

The compressive strength test was performed with the aim of determining the optimum amount of AF to be used in concrete and it was performed in accordance with the respective standards (IS 516 : 1959). A total of three cubical specimens of CC and AFRC with the respective percentages of $\mathrm{AF}$ were used from every batch of the respective curing periods for testing in the compression testing machine at a uniform rate of loading of $14 \mathrm{~N} / \mathrm{mm}^{2}$ and the observed compressive strength values of the specimens were noted down. The surface absorption test was carried out to determine the water absorption rate by calculating the ratio of the gain in weight to the saturated weight which is expressed in percentage and it was performed in accordance with the respective standards (BS 1881 : Part $122: 1983$ ). As the relationship between the porosity and the water absorption capability is proportional, it is necessary to determine the permeability of the concrete specimens with the addition of AF to measure their quality performance (Bhagyasree et al., 2020, Okan \& Cengiz, 2011 and Iman et al., 2018). The cubical specimens were pre-conditioned in an electric oven for a week till the mass of the specimens became constant. These pre-conditioned specimens were submerged in water for about 24 hours and the mass gained by the specimens after that time period were recorded. The RCPT was performed by the method suggested by the respective 
standards (ASTM C1202 - 17). It is often a necessity to determine the impermeability of concrete against chloride ions to identify potential risks of chloride induced corrosion and as a quality control measure so as to evaluate changes in concrete properties (Jemimah \& Prince, 2019 and Haibing et al., 2012). The cylindrical specimens were cut into discs of the specified dimension and were fixed between two reservoirs containing $3.0 \%$ sodium chloride $(\mathrm{NaCl})$ solution in one of the reservoirs which was connected to the negative terminal and $0.3 \mathrm{M}$ of sodium hydroxide $(\mathrm{NaOH})$ solution in the other reservoir which was connected to the positive terminal of the power supply. A sealant was applied around the specimen-cell boundary to avoid any leakage of the solutions so as to maintain an appropriate amount for the entire period of the test. These specimens were subjected to a $60 \mathrm{~V}$ direct current for a time period of 6 hours and the amount of electrical current passing every 30 min at a constant rate through these specimens were recorded. The sorptivity test is used to determine the susceptibility of an unsaturated concrete specimen to the penetration of water and it was performed by the method suggested by the respective standards (ASTM C1585 - 20). It is a simple technique for calculating the water absorption rate by measuring the increase in the mass due to water absorption with respect to time by exposing only one side of the unsaturated concrete specimen to ingress of water by capillary rise (Haibing et al., 2012 and Esam et al., 2014). The cylindrical specimens were cut into discs of the specified dimension and were oven dried at $50^{\circ} \mathrm{C}$ for a week which was followed by cooling these specimens in a sealed container for three days for pre-conditioning. After that, the sides of these specimens were covered with electrical insulation tape and their initial masses were noted down. The specimens were then placed in a tray filled with $5-10 \mathrm{~mm}$ depth of water in such a way that the water should have an access only from the bottom side of the specimen and they were checked at intervals of 1 , $2,3,4,5,10,15,30,60,90,120,150,180,210,240,270,300,330$ and finally at $360 \mathrm{~min}$. After every mentioned interval, the specimens were taken out of the water and their masses 
were recorded after the surface water present was wiped off. The mass gained per unit area over water density was graphed to square root of time elapsed and the slope for the best fit line was taken as sorptivity.

\section{RESULTS AND DISCUSSIONS}

\section{Abaca Fiber Properties}

The knowledge about the physical properties of $\mathrm{AF}$ is a pre-requisite to determine the tenacity for the effective utilization of AF in concrete to use as a construction material in the industry and the values of some of the physical properties of AF have been shown in Table 1 below.

Table 1 Physical properties of AF

\begin{tabular}{|c|c|}
\hline Colour & Light Beige \\
\hline Fiber Length $(\mathrm{mm})$ & 40 \\
\hline Fiber Diameter $(\mu \mathrm{m})$ & $320-450$ \\
\hline Density $\left(\mathrm{kg} / \mathrm{m}^{3}\right)$ & 1520 \\
\hline Tensile Strength $\left(\mathrm{N} / \mathrm{m}^{2}\right)$ & 980 \\
\hline Young's Modulus $(\mathrm{GPa})$ & 40 \\
\hline Specific Strength $(\mathrm{Nm} / \mathrm{kg})$ & 0.65 \\
\hline Specific Stiffness $\left(\mathrm{MPa} /\left(\mathrm{kg} / \mathrm{m}^{3}\right)\right)$ & 26.32 \\
\hline Elongation $(\%)$ & 1.2 \\
\hline Moisture Regain $(\%)$ & 5.8 \\
\hline
\end{tabular}

\section{Compressive Strength Test}

The compressive strength test was carried out for CC and AFRC with $0.5,1.0$ and $1.5 \%$ of AF after 7, 14 and 28 days of curing and the recorded values have been shown in Figure 3. The compressive strength values of $\mathrm{CC}$ and AFRC with the respective percentages of AF obtained after 28 days of curing were 42.04, 49.51, 42.96 and $34.96 \mathrm{~N} / \mathrm{mm}^{2}$ respectively. The compressive strength value obtained for AFRC with $0.5 \%$ of AF was $15.0 \%$ higher compared to $\mathrm{CC}$ and 13.2 and $18.6 \%$ higher compared to AFRC with 1.0 and $1.5 \%$ of AF respectively and hence it has been chosen to be the optimum amount of AF to be used in 
concrete.

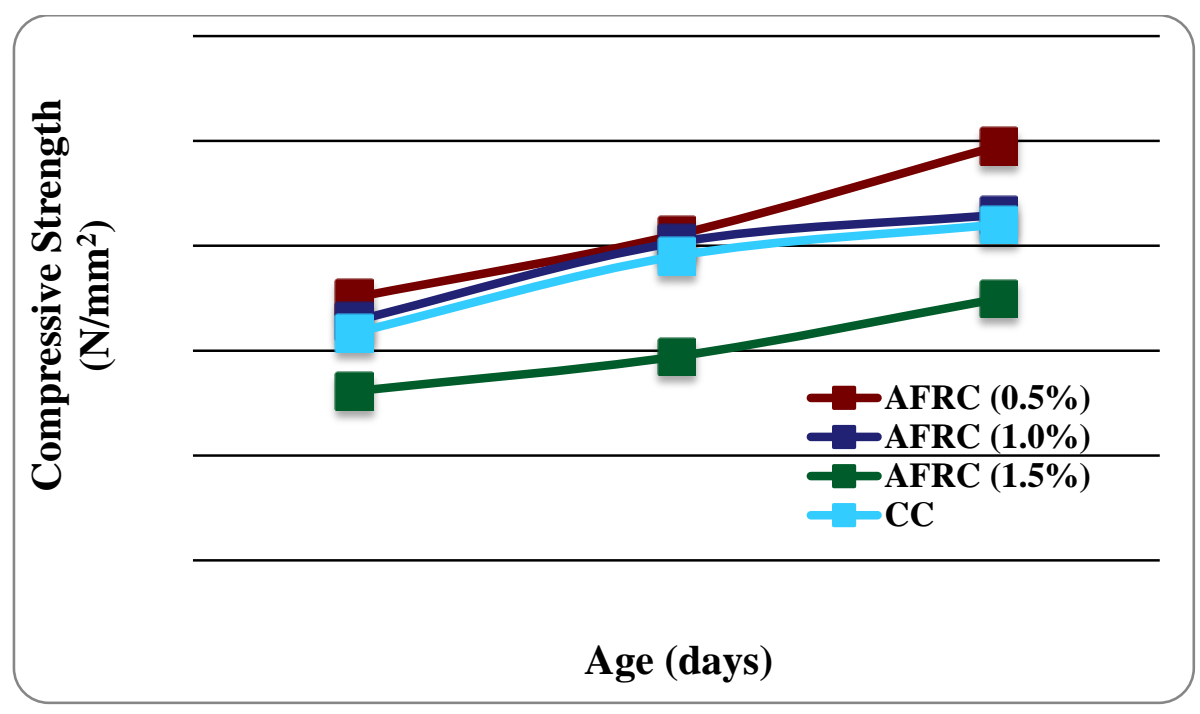

Figure 3 Compressive strength test values of CC and AFRC

\section{Surface Water Absorption Test}

The surface water absorption test was carried out for CC and AFRC with $0.5 \%$ of AF after 3, 7, 28, 56, 90 and 180 days of curing and the recorded values have been shown in Figure 4. The water absorption values of CC and AFRC with $0.5 \%$ of AF obtained after 28 days of curing were 4.22 and $3.91 \%$ respectively indicating that the absorption of water by AFRC with $0.5 \%$ of $\mathrm{AF}$ was $7.63 \%$ lower compared to $\mathrm{CC}$ while the water absorption values obtained for the same after 180 days of curing were 3.90 and $3.68 \%$ respectively indicating that the absorption of water by AFRC with $0.5 \%$ of AF was $5.81 \%$ lower compared to CC which shows low permeability throughout the time period. 


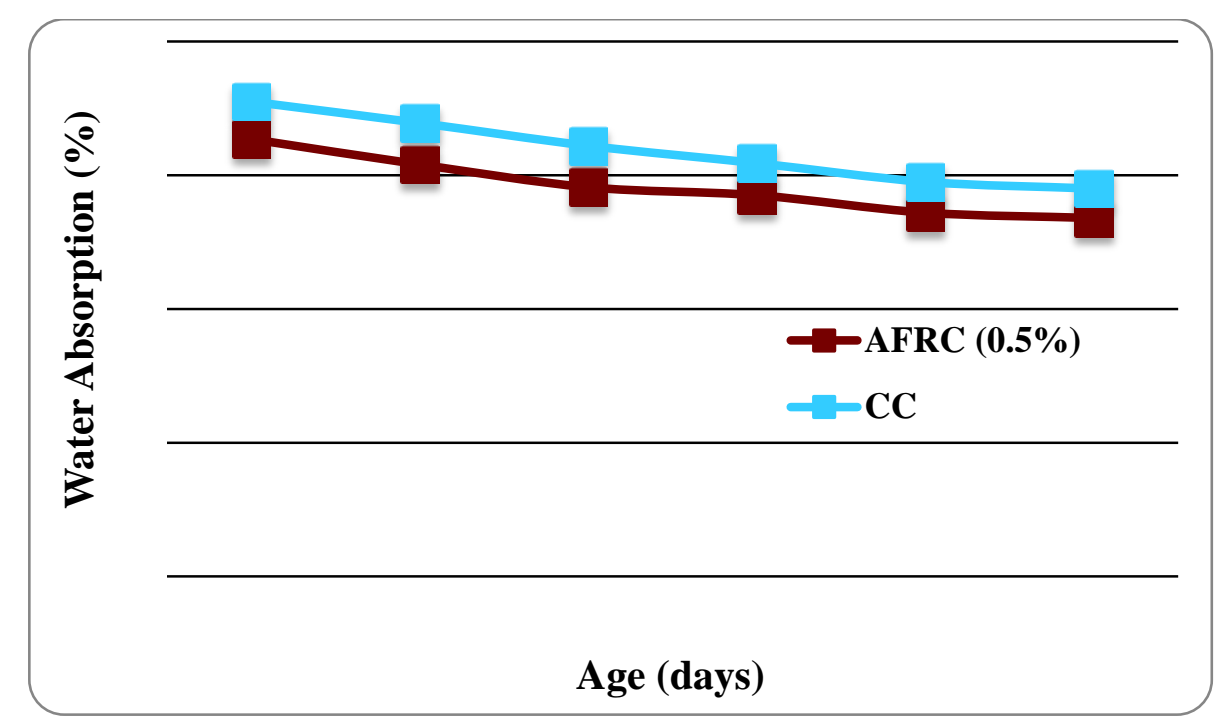

Figure 4 Surface water absorption test values of CC and AFRC

\section{Rapid Chloride Permeability Test}

The RCPT was carried out for CC and AFRC with $0.5 \%$ of AF after 28, 56, 90 and 180 days of curing and the test setup has been shown in Figure 5 while the recorded values have been shown in Figure 6. The charge passed through CC and AFRC with $0.5 \%$ of AF after 28 days of curing were 3896 and $2680 \mathrm{C}$ respectively indicating that the chloride ions penetration through AFRC with $0.5 \%$ of AF was $36.98 \%$ lower compared to $\mathrm{CC}$ while the charge passed through the same after 180 days of curing were 3470 and $1890 \%$ respectively indicating that the chloride ions penetration through AFRC with $0.5 \%$ of AF was $58.96 \%$ lower compared to $\mathrm{CC}$ which shows high resistivity towards chloride ions penetration throughout the time period. 


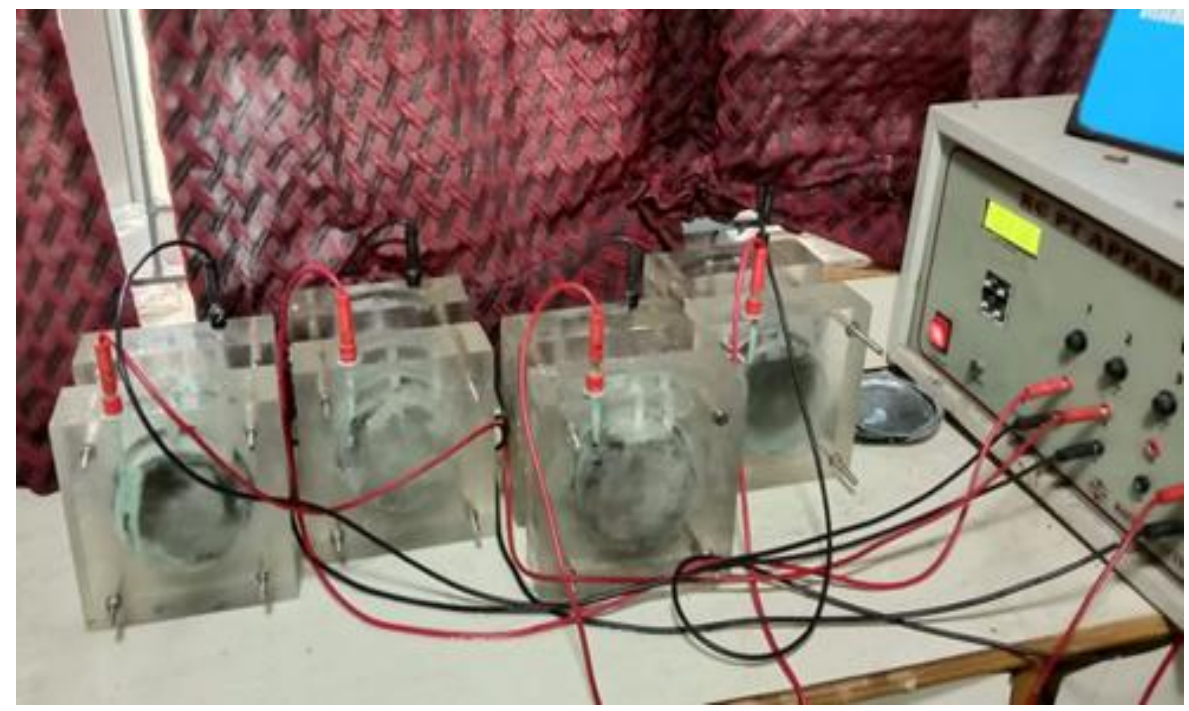

Figure 5 RCPT configuration

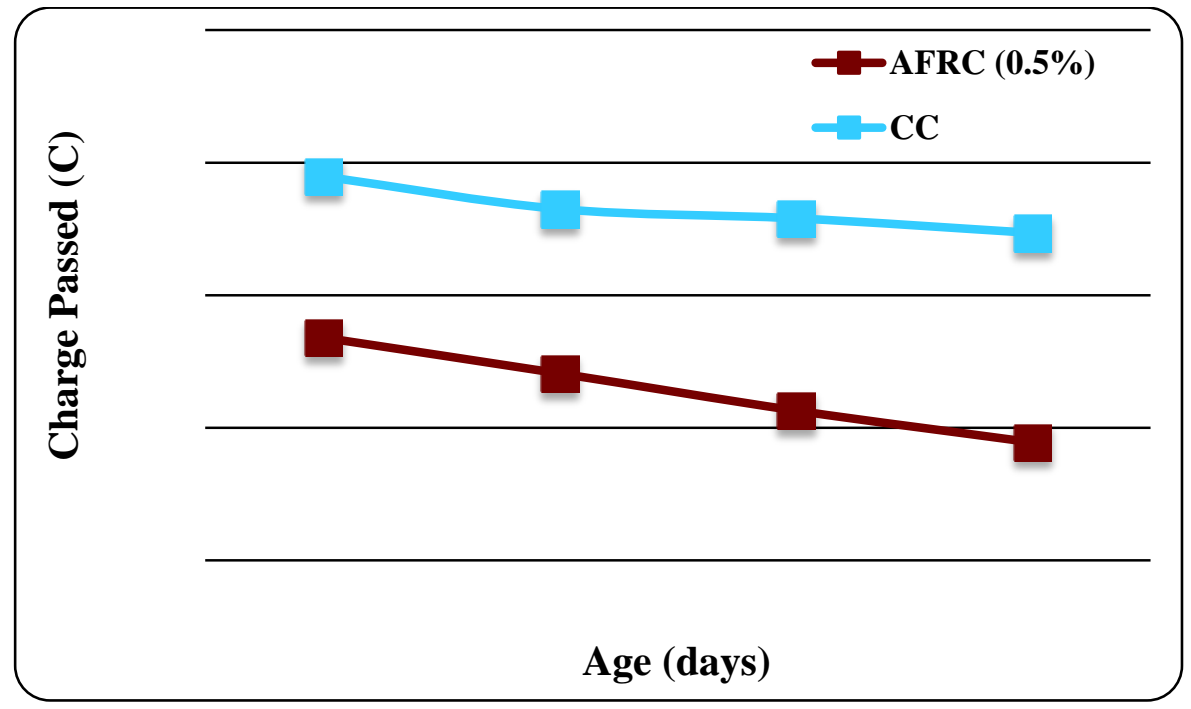

Figure 6 RCPT values of $\mathrm{CC}$ and AFRC

\section{Sorptivity Test}

The sorptivity test was carried out for CC and AFRC with $0.5 \%$ of AF after 3, 7, 28, 56, 90 and 180 days of curing and the test setup has been shown in Figure 7 while the recorded values have been shown in Figure 8. The average sorptivity values of CC and AFRC with 0.5 $\%$ of AF obtained after 28 days of curing were 0.0567 and $0.0438 \mathrm{~mm} / \sqrt{ }_{\mathrm{s}}$ respectively indicating that the capillary rise in AFRC with $0.5 \%$ of AF was $25.67 \%$ lower compared to $\mathrm{CC}$ while the sorptivity values obtained for the same after 180 days of curing were 0.0435 and 
$0.0374 \mathrm{~mm} / \sqrt{\mathrm{s}}_{\mathrm{s}}$ respectively indicating that the capillary rise in AFRC with $0.5 \%$ of AF was $15.08 \%$ lower compared to $\mathrm{CC}$ which shows low rate of absorption of water when exposed to ingress of water by capillary rise throughout the time period.

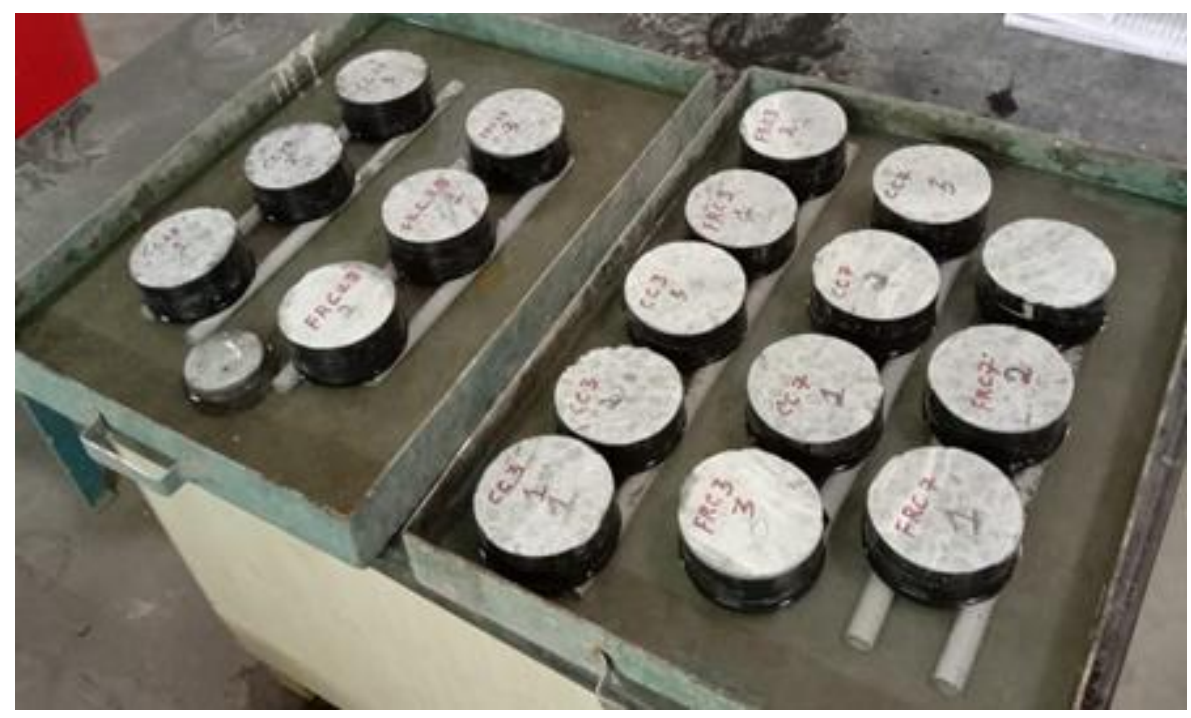

Figure 7 Sorptivity test configuration

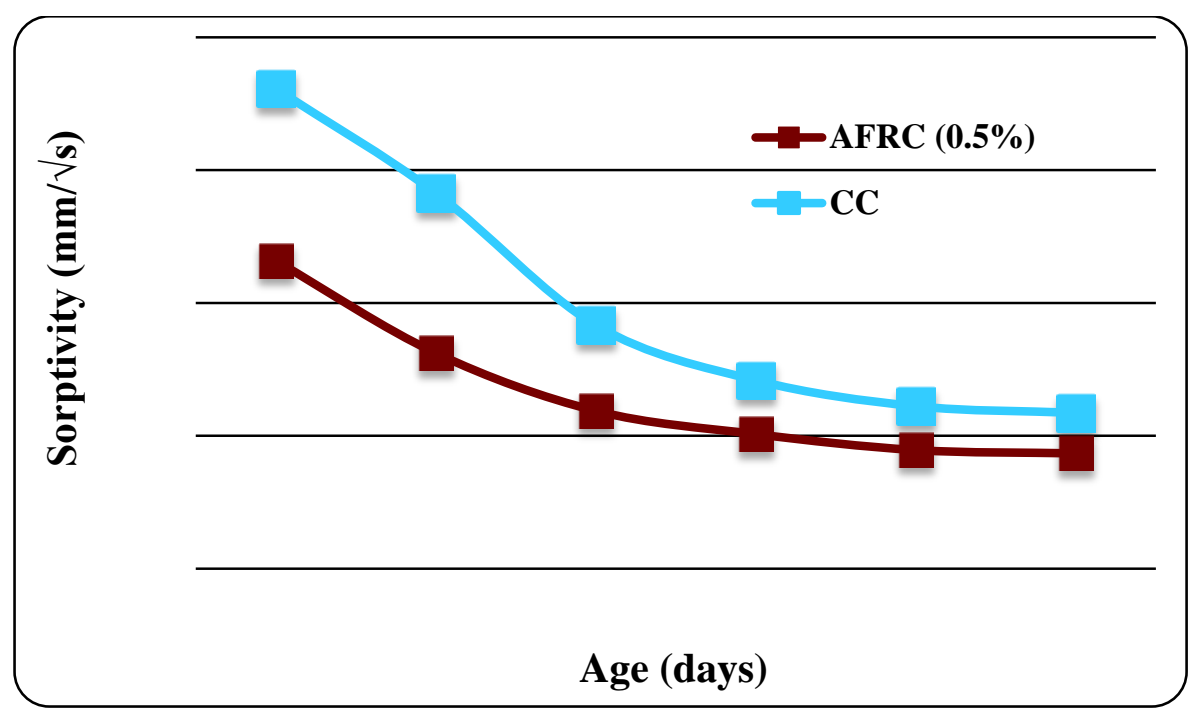

Figure 8 Sorptivity test values of $\mathrm{CC}$ and AFRC 


\section{CONCLUSION}

This experimental study has proven that the addition of AF in concrete aids in bridging across the cracks to increase mechanical strength, toughness, ductility and to obtain improved durability properties. It has been found that it helps to reduce permeability and control plastic and drying shrinkage by arresting the propagation of cracks. The compressive strength value obtained for AFRC with $0.5 \%$ of AF was $15.0 \%$ higher compared to $\mathrm{CC}$ and 13.2 and 18.6 $\%$ higher compared to AFRC with 1.0 and $1.5 \%$ of AF respectively and hence it has been chosen to be the optimum amount of AF to be used in concrete. The surface water absorption by AFRC with $0.5 \%$ of AF was $7.63 \%$ lower after 28 days of curing and $5.81 \%$ lower after 180 days of curing compared to CC which shows low permeability of AFRC in the long run. The charge passed through AFRC with $0.5 \%$ of AF in RCPT was $36.98 \%$ lower after 28 days of curing and $58.96 \%$ lower after 180 days of curing compared to CC which shows high resistivity towards chloride ions penetration while the capillary rise in AFRC with $0.5 \%$ of AF in sorptivity test was $25.67 \%$ lower after 28 days of curing and $15.08 \%$ lower after 180 days of curing compared to $\mathrm{CC}$ which shows low rate of absorption of water when exposed to ingress of water by capillary rise throughout the time period of six months.

\section{REFERENCES}

Stanish, K.D., Hooton, R.D. \& Thomas, M.D.A. 1997. Testing the chloride penetration resistance of concrete: A literature review. FHWA Contract, DTFH61-97-R-00022.

Manlapas, Dr.G.O. 2016. Utilization of abaca fiber as a component material in concrete hollow blocks. International Journal of Current Research, Vol. 8, Issue 11, pp.4084340846.

Afroughsabet, V. \& Ozbakkaloglu, T. 2015. Mechanical and durability properties of highstrength concrete containing steel and polypropylene fibers. Construction and Building Materials, 94: 73-82. 
Asvin Raj, K. 2016. Experimental study on effect of fibres for reinforced concrete. International Journal of Engineering Research and Technology, Vol. 4, Issue 8, ISSN: 2278-0181.

Vajje, S. \& Krishnamurthy, Dr.N.R. 2013. Study on addition of the natural fibers into concrete. International Journal of Scientific and Technology Research, Vol. 2, Issue 11, ISSN 2277-8616.

Sivaraja, M., Kandasamy, et al. 2010. Study on durability of natural fibre concrete composites using mechanical strength and microstructural properties. Bulletin of Materials Science, 33: 719-729.

Balasubramanian, Chandrashekaran, J. \& Senthil Selvan, Dr.S. 2015. Experimental investigation of natural fiber reinforced concrete in construction industry. International Research Journal of Engineering and Technology, Vol. 2, Issue 1, e-ISSN: 2395-0056.

Teng, S., Afroughsabet, V. \& Ostertag, C.P. 2018. Flexural behavior and durability properties of high performance hybrid-fiber-reinforced concrete. Construction and Building Materials, 182: 504-515.

Wei, J., Ma, S. \& Thomas, D'Shawn G. 2016. Correlation between hydration of cement and durability of natural fiber-reinforced cement composites. Corrosion Science, 106: 1-15.

Vijayalakshmi, K., Neeraja, Ch.Y.K., et al. 2014. Abaca fibre. Transactions on Engineering and Sciences, Vol. 2, Issue 9, e-ISSN: 2347-1964.

Richter, S., Stromann, K. \& Mussig, J. 2013. Abaca (musa textilis) grades and their properties - A study of reproducible fiber characterization and a critical evaluation of existing grading system. Industrial Crops and Products, 42: 601-612.

Awwad, E., Mabsout, M., et al. 2012. Studies on fiber-reinforced concrete using industrial hemp fibers. Construction and Building Materials, 35: 710-717.

Saragih, S.W., Lubis, R., et al. 2018. Characteristic of abaca (musa textilis) fiber from aceh 
timur as bioplastic. AIP Conference Proceedings, 2049, 020058.

Müssig, J. \& Stevens, C.V. 2010. Industrial applications of natural fibres: structure, properties and technical applications. Wiley Series in Renewable Resource, ISBN: 978-0470-69508-1.

Indrana, S., Raja, R.E. \& Sreenivasan, V.S. 2014. Characterization of new natural cellulosic fiber from cissusquadrangularis roots. Carbohydrate Polymers, 110: 423-429.

Ramli, M., Kwan, W.H. \& Abas, N.F. 2013. Strength and durability of coconut-fiberreinforced concrete in aggressive environments. Construction and Building Materials, 38: $554-566$.

Coutts, R.S.P. \& Warden, P.G. 1987. Air-cured abaca reinforced cement composites. The International Journal of Cement Composites and Lightweight Concrete, Vol. 9, Issue 2.

IS 10262 : 2009. Concrete mix proportioning - guidelines. Bureau of Indian Standards.

Aruntaş, H.Y., Cemalgil, S., et al. 2008. Effects of super plasticizer and curing conditions on properties of concrete with and without fiber. Materials Letters, 62: 3441-3443.

IS 516 : 1959. Methods of tests for strength of concrete. Bureau of Indian Standards.

BS 1881 : Part 122 : 1983. Testing concrete - method for determination of water absorption. British Standard.

Raj, B., Sathyan, D., et al. 2020. Mechanical and durability properties of hybrid fiber reinforced foam concrete. Construction and Building Materials, 245: 118373.

Karahan, O. \& Atis, C.D. 2011. The durability properties of polypropylene fiber reinforced fly ash concrete. Materials and Design, 32: 1044-1049.

Sadrinejad, I., Madandoust, R. \& Ranjbar, M.M. 2018. The mechanical and durability properties of concrete containing hybrid synthetic fibers. Construction and Building Materials, 178: 72-82.

ASTM C1202 - 17. Standard test method for electrical indication of concrete's ability to resist 
chloride ion penetration. ASTM International.

Carmichael, M.J. \& Arulraj, G.P. 2019. Rapid chloride permeability test on concrete with nano materials. International Journal of Engineering and Advanced Technology, Vol. 8, Issue 3, ISSN: $2249-8958$.

Zheng, H., Li, W., et al. 2012. The effect of a surface-applied corrosion inhibitor on the durability of concrete. Construction and Building Materials, 37: 36-40.

ASTM C1585 - 20. Standard test method for measurement of rate of absorption of water by hydraulic-cement concretes. ASTM International.

Elawady, E., Hefnawy, A.A.E. \& Ibrahim, R.A.F. 2014. Comparative study on strength, permeability and sorptivity of concrete and their relation with concrete durability. International Journal of Engineering and Innovative Technology, Vol. 4, Issue 4, ISSN: 2277-3754. 